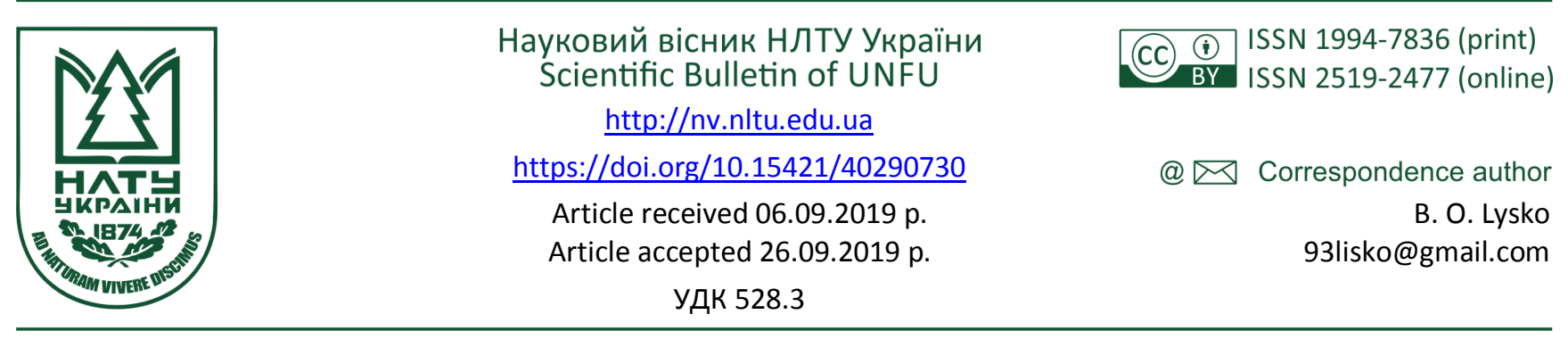

К. О. Бурак', Б. О. Лиско ${ }^{1}$ К. А. Ярош ${ }^{2}$

${ }^{1}$ Івано-Франківський національний технічний університет нафти і газу, м. Івано-Франківськ, Украӥна

${ }^{2}$ Одеський національний політехнічний університет, м. Одеса, Україна

\title{
ОСОБЛИВОСТІ КООРДИНАТНОГО ЗАБЕЗПЕЧЕННЯ РОЗПЛАНУВАЛЬНИХ РОБІТ НА БУДІВНИЦТВI GNSS МЕТОДОМ
}

\begin{abstract}
Запропоновано оптимальну методику створення геодезичної основи на будівництві для однієї чи комплексу споруд, об'єднаних одним технологічним циклом. Наведені технологічні рішення вирішують такі основні проблеми під час виконання розмічувальних робіт на будівельному майданчику, як дотримання принципу підвищення точності при переході від вищого ступеня до нижчого та відсутності впливу похибок, спричинених проектуванням на референц-еліпсоїд та на дотичний циліндр у проекції Гауса-Крюгера. Обгрунтовано можливість виконання основних розмічувальних робіт на всій території триградусної зони RTN методом, забезпечуючи необхідну взаємну точність елементів будівництва 3-5 см. Встановлено, що загальна поправка переходу на площину в проекції Гауса-Крюгера для місцевої системи координат Івано-Франківської області (МСК-26) не перевищує відносну похибку 1/4000. Згідно з отриманим результатом можна рекомендувати картографічні проекції для виконання зйомок навіть у масштабі 1:500. Доведено, що для описаного випадку ортогональну проекцію на горизонтальну площину можна вважати такою, що збігається з топоцентричною системою координат. Хоча при такому виборі координатної площини, напрямки та довжини ліній теоретично повинні відрізнятись на величини, зумовлені відхиленням прямовисної лінії від нормалі при переході на референц-еліпсоїд. Однак, враховуючи розміри будівельного майданчика, для більшості інженерно-геодезичних задач цим впливом можна нехтувати.
\end{abstract}

Ключові слова: GNSS; картографічні проекції; координати; розпланувальні роботи; УСК 2000.

Вступ. Забезпечення необхідної точності виконання вишукувальних та розмічувальних інженерно-геодезичних робіт для будівництва є відповідальним та трудомістким процесом. Зважаючи на високі темпи розвитку міст, з'являється необхідність удосконалення наявних та розроблення нових методів геодезичного забезпечення будівництва, які будуть задовольняти нормативні вимоги точності. Найперспективнішими, на нашу думку, під час створення геодезичної розмічувальної мережі будівництва є використання Real Time Networks (RTN) вимірів (з використанням мереж референцних станцій), про які навіть не згадується у чинних, найбільш сучасних нормативних документах (DBN V.1.3.-2, 2010; Yvanov, 1957) хоча переваги RTN-методів (виміри можна виконувати одним приймачем, одержувати результати без пост опрацювання практично за секунди (Burak \& Lysko, 2017a, 2017b, 2018, Smith et al., 2014; Bonenberg, 2014; Kizil \& Tisor, 2011 тощо) є більш ніж очевидні.

Звичайно координати елементів будівництва відомі у проектній системі координат генплану (будівельної сітки), а геодезична розмічувальна основа, для прикладу в УСК-2000, тоді в разі використання GNSS вимірів, виникає задача встановлення параметрів переходу між цими системами 3 можливістю врахування як похибок вимірів, так і відбракування можливих грубих похибок.
Матеріал і методи дослідження. Для більшості інженерно-геодезичних робіт, зокрема геодезичного супроводу будівництва, є необхідність визначення та винесення в натуру саме натуральних віддалей і кутів (Voitenko, Shults \& Medvedskyi, 2009). Водночас координати опорних пунктів самого генплану відомі у проекції Гауса-Крюгера у поєднанні 3 нормальною висотою (УСК 2000 та похідні від неї 26 місцевих систем координат, в подальшому будемо їх називати картографічними). Визначені за цими картографічними координатами довжини ліній відрізняються від проектних на величину, зумовлену проектуванням на референц-еліпсоїд (поправка $-\Delta_{H}$ ) та на дотичний циліндр у проекції Гауса-Крюгера, або січний у проекції UTM (поправка $\left.\Delta_{\Gamma}\right)$ :

$$
\begin{aligned}
& \Delta_{H}=-S \times \frac{H_{m}}{R_{m}}, \\
& \Delta_{\Gamma}=+S \times \frac{y_{m}^{2}}{2 R_{m}^{2}},
\end{aligned}
$$

де: $H_{m}-$ середня висота виміряної сторони, для будівельного майданчика; $S$ - горизонтальне прокладення віддалі між точками; $R_{m}$ - середній радіус кривизни еліпсоїда; $y_{m}$ - середнє значення із перетворених ординат кінців лінії.

Інформація про авторів:

Бурак Костянтин Омельянович, д-р техн. наук, професор, завідувач кафедри геодезії та землеустрою.

Email: burak4111945@gmail.com

Лиско Богдан Олегович, асистент, кафедра геодезії та землеустрою. Email: 93lisko@gmail.com

Ярош Костянтин Анатолієвич, студент, кафедра прикладної математики. Email: 93lisko@gmail.com

Цитування за ДСТУ: Бурак К. О., Лиско Б. О., Ярош К. А. Особливості координатного забезпечення розпланувальних робіт на будівництві GNSS методом. Науковий вісник НЛтУ України. 2019, т. 29, № 7. С. 151-155.

Citation APA: Burak, K. O., Lysko, B. O., \& Yarosh, K. A. (2019). Features of Coordinate Support for Planning Work on the Gnss Construction Method. Scientific Bulletin of UNFU, 29(7), 151-155. https://doi.org/10.15421/40290730 
Оскільки поправки $\Delta_{\Gamma}$ i $\Delta_{H}$ із протилежними знаками, то частково загальна поправка компенсується. Ця загальна поправка за перехід на площину в проекції Гауса-Крюгера, як і UTM, матиме вигляд

$$
\frac{\Delta_{\text {ped }}}{S}=\frac{\Delta_{\Gamma}+\Delta_{H}}{S}=\frac{y_{m}^{2}}{2 R_{m}^{2}}-\frac{H_{m}}{R_{m}} .
$$

Розглянемо частковий випадок, коли вибір розміщення будівельного майданчика відносно осьового меридіана та висот місцевості збігаються, так, щоб сума цих двох поправок дорівнювала:

$$
\begin{aligned}
\Delta_{\Gamma} & =\Delta_{H} ; \\
S \times \frac{y_{m}^{2}}{2 R_{m}^{2}} & =S \times \frac{H_{m}}{R_{m}} .
\end{aligned}
$$

Звідси, якщо задана величина $H_{m}$, то

$$
y_{m}=\sqrt{2 R_{m} \times H_{m}} \text {. }
$$

Якщо відома величина $y_{m}$, то

$$
H_{m}=\frac{y_{m}^{2}}{2 R_{m}} \text {. }
$$

Отже, якщо будівництво ведеться, для прикладу, на віддалі 14 км від осьового меридіана, то для того щоб поправка (3) дорівнювала нулю, висота поверхні $H_{m}$ повинна дорівнювати

$$
H_{m}=\frac{14^{2}}{2 \times 6371}=15,4 \mathrm{M} .
$$

До того ж, саме такий вибір поверхні відносності рекомендують у роботі (Yvanov, 1957). Водночас середні висоти для цієї місцевості 250-300 м, що робить такий підбір практично не реальним, тому різниця між натуральною довжиною лінії та визначеною за координатами в УСК-2000 буде дорівнювати 1/25 000 довжин ліній на генплані (рис. 1).

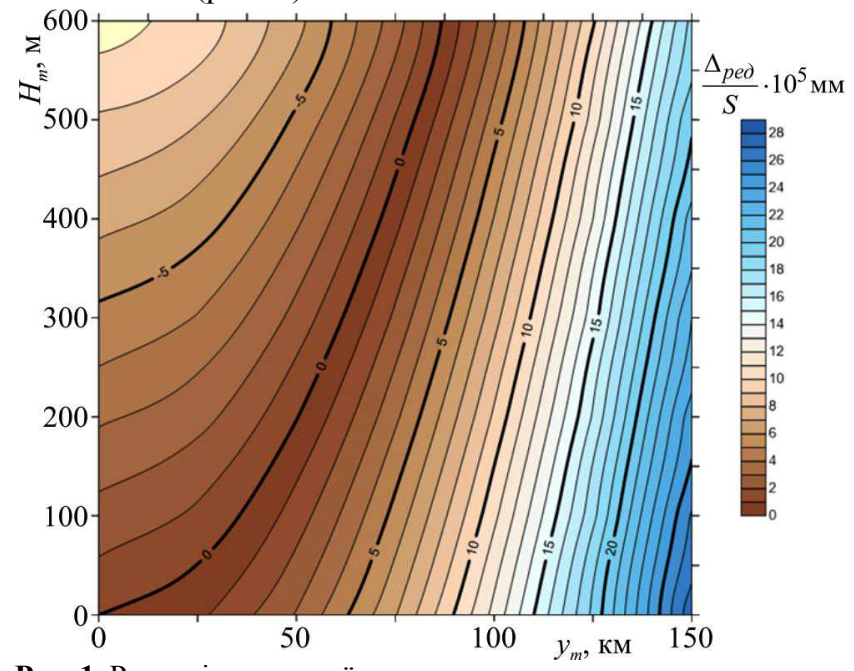

Рис. 1. Розподіл загальної поправки переходу на площину в проекції Гауса-Крюгера залежно від віддалі до осьового меридіана та середньої висоти виміряної сторони

На рис. 1 проілюстровано загальну поправку переходу на площину в проекції Гауса-Крюгера, згідно 3 формулою (3). По осі абсцис відкладено значення віддалі $y_{m}$ від осьового меридіана до проммайданчика в кілометрах, а по осі ординат - середню висоту $H_{m}$ виміряної сторони в метрах. Для наочності отриманих значень всі коефіцієнти, що наведені на графіку, помножені на $10^{5}$ (що відповідає довжині лінії 100 м). Наприклад, за середньої висоти будівельного майданчика 300 м та його віддаленості від осьового меридіана 100 км максимальна поправка при винесенні ліній довжиною 100 м, за редукування становить - 10 мм. За більших довжин ліній значення поправки буде пропорційно зростати, за тих же умов поправка для віддалі 300 м становитиме 30 мм, проте відносна похибка не перевищить 1/10000 для усіх випадків. Аналіз рис. 1 показує, що у триградусній зоні максимальна відносна похибка не перевищує $1 / 4000$, тому при виконанні зйомок, навіть у масштабі 1:500, нею можна нехтувати. Це ж стосується і першого етапу основних розпланувальних робіт. Цей етап полягає в тому, що від геодезичних пунктів виносять і закріпляють головні розмічувальні осі. Нормативна точність цих робіт повинна становити 3-5 см. Згідно з отриманими результатами, які відображені на рис. 1, можна стверджувати, що необхідна точність на першому етапі розпланувальних робіт досягається навіть на краю зони при полярних віддалях до 100 м. Водночас на віддалі до 50 км від осьового меридіана можна виносити в натуру базисні сторони довжиною навіть до 1 км.

Також варто зазначити, що при пошуку параметрів трансформування для цих випадків масштабний коефіцієнт $m$ можна приймати таким, що дорівнює 1 . Проте для забезпечення міліметрової точності, яка потрібна для детальних розпланувальних робіт, картографічними координатами можемо користуватись тільки у вузькій смузі - від 40 до 60 км від осьового меридіана (за середньої висоти майданчика 300 м).

Розглянемо випадок, коли необхідно враховувати різницю у довжинах ліній, винесених за картографічними координатами в УСК-2000 і проектними довжинами, наприклад на краю триградусної зони при полярних віддалях більше 100 м, а також на другому етапі розпланувальних робіт.

Нормативна точність другого етапу розпланувальних робіт (винесення основних осей) становить 3-5 мм (DBN V.1.3.-2, 2010; Manual, 2019). За результатами досліджень точності RTK RTN вимірів у мережі, наприклад System Solutions (Burak \& Lysko, 2017a, 2017b, 2018), було встановлено, що середня квадратична похибка виміру кута та віддалі не перевищує $m_{\kappa y m}=4,3$ " та $m_{\text {вid }}=3,2$ мм відповідно. Для статичних, синхронних вимірів досягнута точність навіть більша (Savchyn \& Duma, 2016; Medvedskyi, 2010), що дає змогу використовувати GNSS виміри і на другому етапі розмічувальних робіт, або хоча б як контроль вимірів електронним тахеометром.

Для забезпечення високої точності розпланувальних робіт (3-5 мм) рекомендуємо додатково використовувати топоцентричну прямокутну систему координат (Savchuk, 2000). Ця необхідність обгрунтовується специфікою задачі: порівняно малі віддалі між точками (100200 м) та використання GNSS приймача. У такому разі трансформування пунктів необхідно виконувати в два етапи: спочатку визначити геоцентричні координати опорних базисів (проектні координати яких відомі згідно $з$ технологічними кресленнями), після чого за формулами (13)-(19) перейти до запропонованої координатної площини. За неї приймається площина не геодезичного горизонту, а горизонтальна площина, як на генплані, із віссю $x$, напрямленою у площині геодезичного меридіана. Ця математична основа буде найкращим рішенням для геодезичного забезпечення окремого будівельного майданчика. У разі використання ортогональної проекції на горизонтальну площину у прямокутній декартовій системі координат у виміряні величини не вводяться поправки для переходу на поверхню відносності та на 
площину проекції Гауса-Крюгера. Тому при аналітичній підготовці проекту будівництва, знайдені за плановими координатами в цій проекції довжини і напрямки, будуть дорівнювати їх технологічним розмірам, що дає змогу трансформувати проектні координати елементів у систему, із якою працює GNSS без урахування масштабного коефіцієнта за формулами:

$$
\left\{\begin{array}{l}
X^{\prime}{ }_{i}=X_{0}+X_{i} \cos Q-Y_{i} \sin Q \\
Y^{\prime}{ }_{i}=Y_{0}+Y_{i} \cos Q+X_{i} \sin Q
\end{array}\right.
$$

де $X_{i}, X_{i}^{\prime} i Y_{i}, Y_{i}^{\prime}-$ координати точки $i$ в топоцентричній системі координат та генплану.

Доведемо, що у нашому випадку ортогональна проекція на горизонтальну площину може вважатись такою, що збігається 3 топоцентричною системою координат (рис. 2). При такому виборі координатної площини, напрямки та довжини ліній теоретично повинні відрізнятись на величини, зумовлені відхиленням прямовисної ліній від нормалі при переході на референц-еліпсоїд (Smith et al., 2014; Bonenberg, 2014). Однак, враховуючи розміри будівельного майданчика, для більшості інженерно-геодезичних задач, які розв'язують на будівництві, цим впливом можна нехтувати.

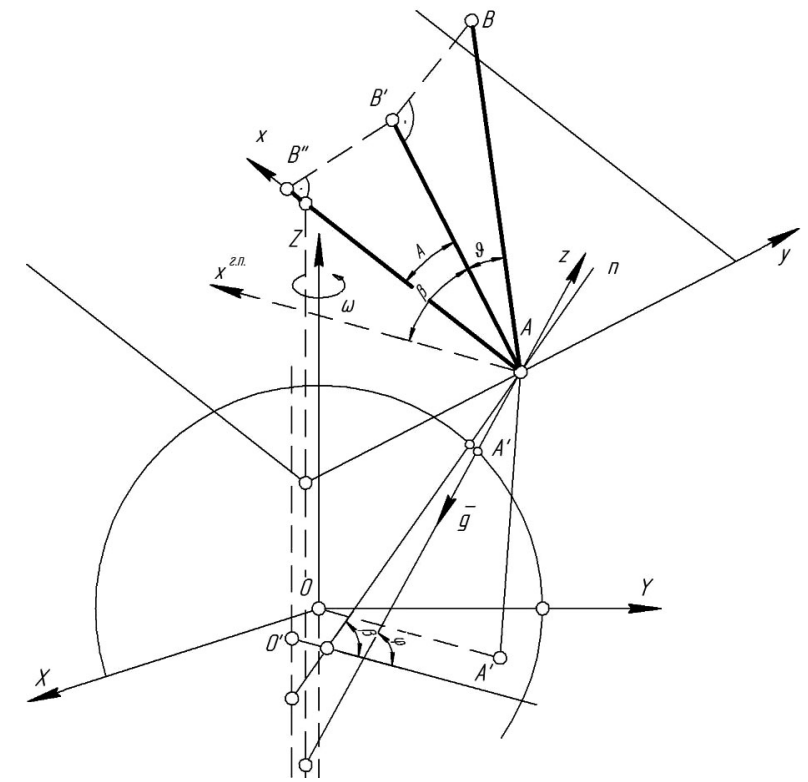

Рис. 2. Топоцентрична система координат генплану: $\mathrm{AB}$ - натуральна довжина лінії; АВ' - горизонтальне прокладення, визначене за проектними координатами; $\mathrm{AB}$ " - топоцентрична координата точки В, яку виносять в натуру; В"В - координата у-топоцентрична; $\mathrm{Ax}$ - геодезичний меридіан; $\mathrm{Ax}{ }^{\text {г.п. }}$ - вісь $\mathrm{x}$ генплану; $\mathrm{Az}$ - напрямок прямовисної лінії; $\mathrm{An}$ - напрямок нормалі до референт-еліпсоїда; $\mathrm{AA}^{\prime}$ - висота $\mathrm{H}_{\mathrm{m}}$

Поправку в горизонтальний кут за відхилення прямовисної лінії від нормалі обчислюють за формулою

$$
v=(\eta \cos A-\xi \sin A) \operatorname{ctg} z,
$$

де: $z=90-v, v-$ виміряний кут нахилу лінії; $A$ - азимут напрямку; $\eta, \xi$ - складові відхилення прямовисної лінії проекції на площини першого вертикалу та меридіана.

Оскільки розмічування ведеться на розпланованій місцевості, приймемо, що максимальний ухил будівельного майданчика не перевищує $5^{\circ}$, тоді максимальне значення поправки у горизонтальний кут за відхилення прямовисної лінії від нормалі становитиме

$$
v_{\max }=\eta \operatorname{ctg} z=0,09 \eta \text {. }
$$

Середнє відхилення прямовисних ліній на території України становить 4-5", а у гірських районах може сягати 30" (Dvulit, Dzhuman \& Smelianets, 2012), що впливає на поправку у визначений напрямок не більше 1". Згідно 3 цим розрахунком можна стверджувати, що впливом на напрямки, зумовленим відхиленням прямовисної ліній із нормаллю, можна нехтувати, коли розпланувальні роботи виконують на території, обмеженій розмірами будівельного майданчика.

Аналогічно у більшості випадків $є$ неістотним i вплив різниці у відхиленнях виска на кінцях лінії, на величину горизонтального прокладення - $\delta S$, який можна визначити за формулою

$$
\delta S=\frac{u_{2}-u_{1}}{\rho "} H_{m}
$$

За умови $\delta S \leq 1$ мм максимальне значення $\left(u_{2}-u_{1}\right)$, яке можна не враховувати залежно від висоти промислового майданчика, знаходимо з виразу

$$
\left(u{ }_{2}-u{ }_{1}\right)_{\max }=\frac{\rho "}{H_{m}} \text {. }
$$

Наприклад, для висот до 400 м $\left(u{ }_{2}-u{ }_{1}\right)_{\max }=\rho " / H_{m}$ допускається до 0,5", більша величина ніж $0,5 "$ на порівняно невеликих віддалях, навіть до 1 км, можлива тільки в аномальних районах. Тому враховувати цей фактор потрібно тільки для унікальних об'єктів, коли точність розпланувальних робіт повинна бути меншою 1 MM.

Оскільки розміри проммайданчиків, не говорячи вже про окремі їх комплекси, не перевищують 1 км, то вплив, зумовлений різницями відхилень висків на кінцях лінії, не перевищує вимоги точності для детальних розпланувальних робіт. Цей факт дає змогу приймати при розрахунках прямовисні лінії за нормалі до геодезичного горизонту.

Під час розпланування житлових масивів, чи великих об'єктів складної конфігурації використання проектної системи координат (генплану), в якій осі координат паралельні лініям забудови, є зручним з точки зору спрощення розрахунків для виносу, як осей споруд, так і підземних комунікацій.

Рис. 3, запозичений із відомої монографії Барана (Baran, 2012), переконливо показує переваги використання системи координат генплану під час розмічувальних роботах. Однією з них є те, що розрахунок координат пункту у випадку паралельності лініям забудови осей координат зводиться до сумування технологічних розмірів будівлі та запроектованих віддалей між ними, що практично усуває можливість помилок під час обчислень. За наявності робочих креслень в AutoCad, координати можна визначити безпосередньо 3 комп'ютера, сформувавши автоматично файл для розмічувальних робіт за допомогою електронного тахеометра чи GNSS приймача.

Результати дослідження. Зважаючи на це, можна запропонувати таку оптимальну методику розпланувальних робіт при забудові промислових майданчиків. За технологічними розмірами визначаємо проектні координати $-x_{2 . n}, y_{2 . n}$ всіх пунктів наявної геодезичної основи і кінців базисних ліній, паралельних до осей генплану, від яких будемо вести розпланування споруди, або комплексу, пов'язаного єдиним технологічним циклом. Як це описано в роботі (Burak, 2011), виносимо та закріплюємо в натурі базову лінію $A B$. Враховуючи вірогідність знищення одного 3 пунктів при проведені земляних робіт, у натуру бажано винести і закріпити мінімум дві базові лінії. Наприклад, для випадку, зобра- 
женого на рис. 3 , доцільно винести як базові пункти $A$, $B$ і $C$ - на перетині створів наявної будівлі та запроекто- ваних точок основної осі 16-15. Точки $A$ та $C$ можна винести навіть і за картографічними координатами.

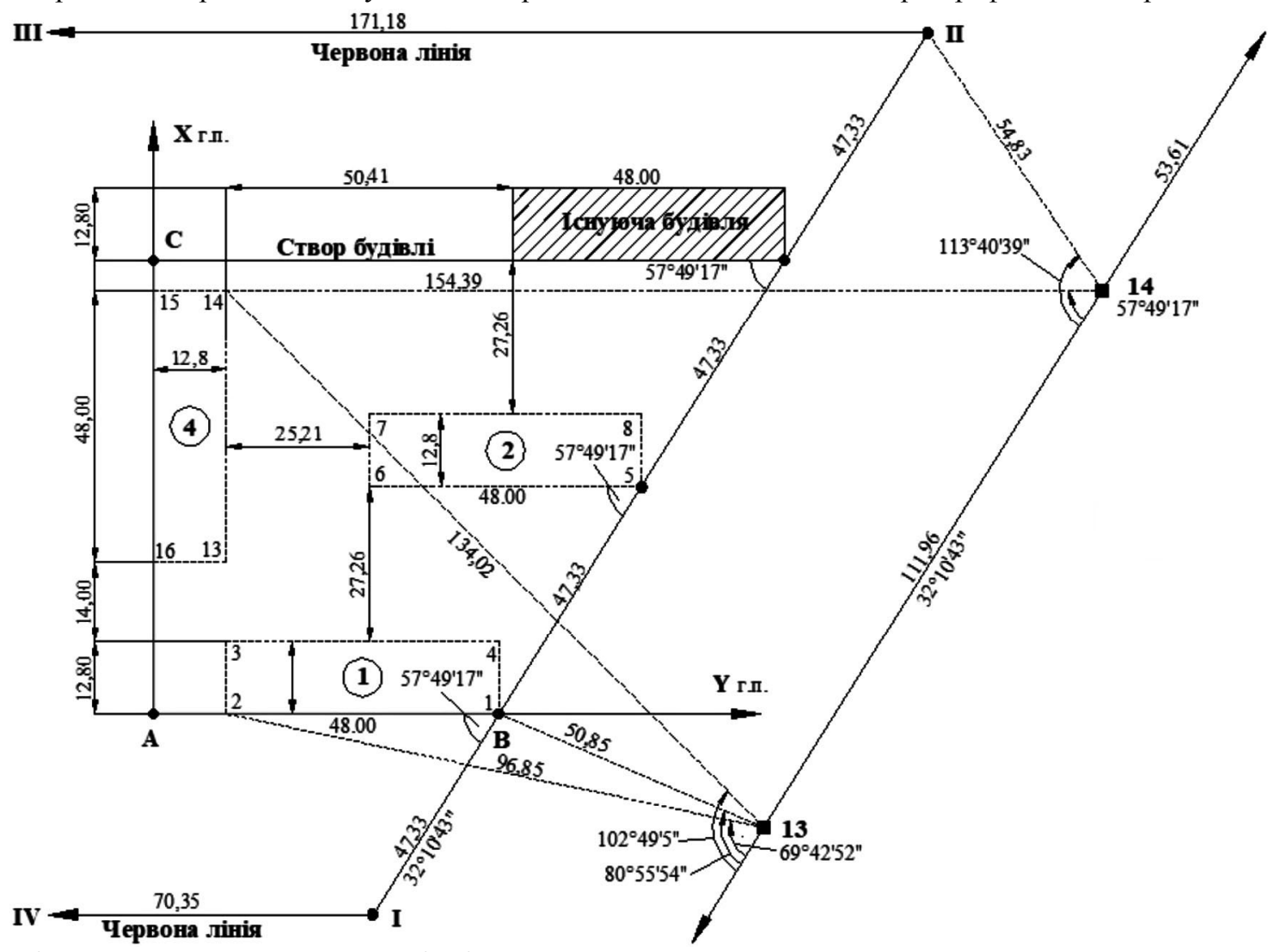

Рис. 3. Розмічувальне креслення групи будинків мікрорайону: 13-14 - пункти геодезичної основи; I-VI - пункти червоних ліній

Після закріплення базисів у натурі визначаємо координати методом GNSS - $X_{A}, X_{B}, Y_{A}, Y_{B}$ - геоцентричні координати точок базису, $B_{A}, L_{A}, B_{B}, L_{B}$ - геодезичні координати точки $B$ базису, а також для контролю координати точок червоних ліній, від яких виконано проектування розміщення споруд.

Обов'язково аналізуємо одержані координати точок червоних ліній на можливі грубі помилки у координатах, визначаючи за геоцентричними координатами GNSS віддалі між ними (за формулою (1)) та порівнюючи їх 3 технологічними розмірами. У разі виявлення помилок, узгоджуємо це питання з проектантом.

Для винесення контуру споруди - основних осей знаходимо за проектними координатами точок, які будуть закріпляти контур споруди, і проектними координатами точок базису, їх топоцентричні координати за формулами, які представимо у вигляді:

$$
x_{\text {T.L. }}=S \cos A, y_{\text {T.ц. }}=S \sin A,
$$

де: $S$ - віддаль від початку координат до точки; $A$ - азимут до точки.

Віддаль від початку координат до точки визначають за формулою

$$
S=\sqrt{\Delta x_{A-1}^{2}+\Delta y_{A-1}^{2}},
$$

де $\Delta x_{A-1}, y_{A-1}-$ різниця проектних координат точки $A$ (початку проектної системи координат) i 1, яку виносять в натуру.

Азимут до точки визначають за формулою

$$
A=A_{\text {nоч }}+\beta,
$$

де $\beta$ - азимут, що дорівнює $\beta=\operatorname{arctg} \frac{\Delta y_{A-1}}{\Delta x_{A-1}} ; A_{n о ч}-$ геодезичний (від площини геодезичного меридіану) ази- мут базисної лінії $A B$, який визначається із результатів GNSS вимірів на точках базису. Для нашого випадку його можна обчислити за формулами:

$$
\left|\begin{array}{l}
x_{B}^{\prime} \\
x_{B}{ }_{B}
\end{array}\right|=P_{B}^{\prime}\left|\begin{array}{l}
X_{A}-X_{B} \\
Y_{A}-Y_{B}
\end{array}\right|,
$$

де: $P^{\prime}{ }_{B}$ - матриця перетворення; $X_{A}, X_{B}, Y_{A}, Y_{B}$ - геоцентричні координати точок базису;

$$
P_{B}^{\prime}=\left|\begin{array}{ccc}
-\sin B_{B} & -\sin B_{B} \sin L_{B} & \cos B_{B} \\
-\sin L_{B} & \cos L_{B} & 0 \\
\cos B_{B} \cos L_{B} & \cos B_{B} \sin L_{B} & \sin B_{B}
\end{array}\right|,
$$

де $B_{B}, L_{B}$ - геодезичні координати точки $B$ базису.

Відповідно, геоцентричні координати проектних точок, які потрібно винести в натуру, використовуючи GNSS приймач, знаходимо за відомими формулами:

$$
\left|\begin{array}{l}
X_{1} \\
Y_{1}
\end{array}\right|=\left|\begin{array}{l}
X_{A} \\
Y_{A}
\end{array}\right|+P\left|\begin{array}{l}
x_{T . L .} \\
y_{T . Ц .}
\end{array}\right|,
$$

де $P$ - матриця повороту, елементи якої геодезичні координати вихідної точки;

$$
P^{\prime}{ }_{B}=\left|\begin{array}{ccc}
-\sin B_{A} & -\sin L_{A} & \cos B_{A} \cos L_{A} \\
-\sin B_{A} \sin L_{A} & \cos L_{A} & \cos B_{A} \sin L_{A} \\
\cos B_{A} & 0 & \sin A
\end{array}\right|,
$$

де $B_{A}, L_{A}$ - геодезичні координати точки $B$ базису.

Для обчислень геоцентричних координат за координатами точок генплану ми розробили програмний комплекс, який дає змогу скоротити час на проведення обчислень. Використовуючи GNSS приймач, за знайденими координатами WGS виносимо і закріплюємо в натурі головні та основні осі.

Для контролю виносимо ці ж точки від базових ліній електронним тахеометром, оскільки це описано в 
роботах (Burak \& Lysko, 2018; Kizil \& Tisor, 2011). Збіг у натурі точок, винесених GNSS та розпланованих електронним тахеометром методом від базисної лінії, буде відрізнятися контролем як для польових, так і камеральних робіт.

Пропонована методика випробувана під час детального розпланування контуру будівлі як на експериментальному полігоні, так і при винесенні в натуру контурів (основних осей) реальних будівель. Результати підтвердили високу оперативність та точність виконання робіт. Потреба в редуціюванні винесених пунктів, що закріплюють контур споруди, якщо і виникала, то редукційні величини в усіх випадках були меншими 10 мм. Ці результати було отримано при використанні примусового та оптичного центрування GNSS приймача.

Висновки. Розроблено практичні рекомендації для створення геодезичної розмічувальної основи на будівництві, що забезпечують необхідну планову точність згідно з чинними нормами та значно зменшують затрати часу на виконання геодезичних робіт на будівельному майданчику.

Доведено можливість виконання основних розмічувальних робіт на всій території триградусної зони RTN методом, із забезпеченням необхідної взаємної точності (3-5 см) елементів будівництва.

Встановлено, що загальна поправка переходу на площину в проекції Гауса-Крюгера для місцевої системи координат Івано-Франківської області (МСК-26) не перевищує відносну похибку 1/4 000.

\section{Перелік використаних джерел}

Baran, P. I. (2012). Engineering geodesy. Kyiv: Vipol. [In Ukrainian]. Bonenberg, L. K. (2014). Closely-coupled integration of Locata and GPS for engineering applications. PhD thesis. University of Nottingham. $184 \mathrm{p}$.

Burak, K. O. (2011). Planning and executive shooting technology using TPS. Geodesy, Cartography and Aerial Photography, 75, 5357. [In Ukrainian].

Burak, K. O., \& Lysko, B. O. (2017a). Exploring the accuracy of lengths constructions when solving the engineering geodesy issues with RTN method. Geodesy. Cartography and Aerial Photography, $85,5-12$

Burak, K. O., \& Lysko, B. O. (2017b). Results of investigating the accuracy of rtn methods of gnss measurements by the single basic solution. their usage for the marking works during the construction. Scientific Bulletin of UNFU, 27(6), 145-150. https://doi.org/10.15421/40270629

Burak, K. O., \& Lysko, B. O. (2018). The possible uses of RTN solutions for markup works on construction. Geodesy, Cartography and Aerial Photography, 87, 18-23.

DBN V.1.3.-2:2010. Systema zabezpechennia tochnosti heometrychnykh parametriv $v$ budivnytstvi. Heodezychni roboty $v$ budivnytstvi. Kyiv: Minrehionbud Ukrainy. [In Ukrainian].

Dvulit, P. D., Dzhuman, B. B., \& Smelianets, O. V. (2012). Model of gravimetric components of deviations of straight lines of the territory of Ukraine according to EGM 2008. Heodynamika, 1(12), 30 35. [In Ukrainian]

Kizil, U., \& Tisor, L. (2011). Evaluation of RTK-GPS and Total Station for applications in land surveying. Journal of Earth System Science, 120, 215-221.

Manual. (2019). Topographic Survey Manual in Scales 1: 5000, 1: 2000, 1: 1000 and 1: 500. Retrieved from: http://www.geoguide.com.ua/basisdoc/basisdoc.php?part=tgo\&art= $\underline{350}$

Medvedskyi, Yu. V. (2010). Methods of experimental studies of the accuracy of construction of geodetic base on the mounting horizon GNSS-method. Inzhenerna heodeziia, 56, 53-56.

Savchuk, S. H. (2000). Higher geodesy (Spheroid Surveying). Lviv: Liha-Pres. [In Ukrainian].

Savchyn, I. R., \& Duma, M. V. (2016). Optimization of the GNSS reference network of the Dniester HPP. Geodesy, Cartography and Aerial Photography, 10, 17-24. [In Ukrainian].

Smith, D., Choi, K., Prouty, D., et al., (Eds.) (2014). Analysis of the TXDOT RTN and OPUS-RS from the geoid slope validation survey of 2011: Case study for Texas. Journal of Surveying Engineering. 140. https://doi.org/10.1061/(ASCE)SU.1943-5428.0000136, $\underline{05014003}$

Voitenko, S. P., Shults, R. V., \& Medvedskyi, Yu. V. (2009). Modern methods of transfer of coordinates of spatial geodetic network points to the mounting horizon. Budivnytstvo Ukrainy, 9, 21-24. [In Ukrainian].

Yvanov, N. Y. (1957). O vybore poverkhnosty proektyrovanyia tryanhuliatsyy pry ynzhenerno-heodezycheskykh yzyskanyiakh y horodskykh semkakh. Heodezyia y kartohrafyia, 2, 36-39. [In Russian].

K. O. Burak1, B. O. Lysko', K. A. Yarosh

${ }^{1}$ Ivano-Frankivsk National Technical University of Oil and Gas, Ivano-Frankivsk, Ukraine

${ }^{2}$ Odessa National Polytechnic University, Odessa, Ukraine

\section{FEATURES OF COORDINATE SUPPORT FOR PLANNING WORK} ON THE GNSS CONSTRUCTION METHOD

Some practical recommendations for building the geodesic marking construction base, that will provide the accuracy and save time of geodesic works on the construction site, are provided in the article. These recommendations will allow refusing from building the classic construction netting and conducting planning works with GNSS receiver by using RTN methods and modern electronic total stations (TS). To build the graticule on the construction site, we should mark two basis AB and CD in-situ with GNSS receiver, so they are parallel to the $\mathrm{x}$ and $\mathrm{y}$ axes of the general plan on which the site is projected. Then, we will mark the axes, using the method from the basic line as described in the work (TS). To solve the problem, one has to know only the coordinates $\mathrm{x}$ and $\mathrm{y}$ of one basis point and set the position angle of the line to $0^{\circ}$ or $90^{\circ}$. Theoretically all planning works may be done from one base line, but we recommend to set at least two lones in order to provide the visibility on entire site including the possibility of losing important points during the construction works. During planning and marking works, GNSS measurements on the nearest observation points are made on the short distance from each other (not more than $1000 \mathrm{~m}$ ), so the points will be located in ionospheric conditions and there will be a chance to see the same satellites. It allows confirming that influence of errors, entailed by ionospheric delays and satellite clock wrong time will be significantly decreased because of the compensation of their systematic component that will improve the accuracy of set base lines. The information mentioned above was proved by our research. According to research results, when following the recommendations (adequate amount of measurement averaging, distance to the closest permanent stations and geometry of their allocation), it is possible to get the accurate mutual location $3.18 \mathrm{~mm}$ (including the error of line orientation), and the accuracy of setting vectors $-2.52 \mathrm{~mm}$ on the distances less than $200 \mathrm{~m}$. It is important to remember that points A, B, C, and D are set without such errors as device and viewfinder centering, as well as error of benchmark data.

Keywords: GNSS; map projections; coordinates; planning work; USC 2000. 